\title{
PREDIKSI AWAL MUSIM HUJAN DI JAWA MENGGUNAKAN DATA LUARAN REGIONAL CLIMATE MODEL VERSION 3.1 (REGCM3)
}

\author{
MONSOON ONSET PREDICTION ON JAVA USING REGIONAL \\ CLIMATE MODEL VERSION 3.1 (REGCM3)
}

\author{
Fithriya Yulisiasih Rohmawati ${ }^{1}$, Rizaldi Boer ${ }^{1,2}$ dan Akhmad Faqih ${ }^{1,2}$ \\ ${ }^{1}$ Departemen Geofisika dan Meteorologi, \\ Gedung FMIPA, Jl. Meranti Wing 19 Lv. 4 Kampus IPB Darmaga Bogor 16680 \\ ${ }^{2}$ Centre for Climate Risk Management in Southeast Asia and Pacific (CCROM-SEAP) IPB \\ * Corresponding author, email: fithr4103@gmail.com
}

Penyerahan Naskah: 4 April 2013

Diterima untuk diterbitkan: 3 Februari 2014

\begin{abstract}
Monsoon onset information plays an important role in setting up planting strategy for achieving optimum yield. This study aimed to develop forecasting model for the monsoon onset in main rice growing area of Java used Regional Climate Model Version 3.1 (RegCM3). The forecasting models of the monsoon onset and September-Oktober-November (SON) rainfall data were developed using regression model that have the highest coefficient determination and the models were tested using likelihood ratio test. It was found that the forecasting models of the monsoon onset and September-Oktober-November rainfall data were polynomial orde 2 or cuadratic that have coefficient determination 69\%, 74\%, 80\% and 86\%. Likelihood ratio test found that RegCM3 rainfall data was not significantly different with observation rainfall data $(\alpha=0.05)$. Onset in Java between $25^{\text {th }}$ until $34^{\text {th }}$ of 10-days period (early September until early December).
\end{abstract}

Keywords: Java, monsoon onset, RegCM3, SON rainfall data

Sitasi: Rohmawati F.Y., Boer R. dan Faqih A. 2014. Prediksi awal musim hujan di Jawa menggunakan data luaran Regional Climate Model Version 3.1 (RegCM3). J Agromet Indonesia. 28(1):17-22.

\section{PENDAHULUAN}

Pulau Jawa berada di bagian selatan Indonesia dan memiliki luas sekitar $139.000 \mathrm{~km}^{2}$. Wilayah tersebut merupakan daerah penghasil padi di Indonesia dengan 60,3\% sawah berbasis irigasi dan 26,5\% berbasis tadah hujan (Wahyunto, 2009). Pengelolaan sawah kedua jenis tersebut sangat terkait dengan informasi awal musim hujan (AMH) dikarenakan tanaman padi memerlukan jumlah air yang banyak yaitu sekitar $600-1.200 \mathrm{~mm}$ selama 90-100 hari masa tanam (De Datta, 1981).

AMH merupakan informasi penting bagi sektor pertanian di Jawa (Boer et al., 2007). Informasi AMH diperlukan oleh petani untuk menentukan pola dan strategi tanam (Boer dan Subbiah, 2005). Selain itu, AMH digunakan untuk menentukan musim tanam yang tepat. Ketika tahun-tahun El Niño, AMH mundur sehingga mengakibatkan kegagalan panen. Bagi sawah irigasi, informasi AMH diperlukan untuk mengu- rangi resiko gagal panen pada periode tanam kedua yang beririsan dengan musim kemarau (April-Juli) terutama bagi sawah yang jauh dari sumber pengairan irigasi (Moron et al., 2009).

Hambatan utama dalam penelitian mengenai AMH ialah kesulitan untuk mendapatkan data observasi yang lengkap dan menyeluruh. Terkadang data observasi di daerah tertentu tersedia, akan tetapi kurang lengkap/memadai untuk dianalisis, atau bahkan data observasi tidak tersedia akibat tidak ada stasiun klimatologi di daerah tersebut. Semakin banyak/lengkap stasiun yang digunakan dalam mengolah data iklim, maka kesalahan bias yang terjadi akan semakin kecil (Swarinoto et al., 2009). Oleh karena itu, diperlukan solusi untuk mendapatkan data iklim yang lengkap dan menyeluruh. Salah satu cara yang dapat ditempuh adalah mendapatkan data iklim dari model iklim regional (RegCM3). Penelitian ini bertujuan melakukan prediksi AMH tahun 1962 sampai 2001 meng-gunakan data curah hujan luaran RegCM3. 


\section{METODE PENELITIAN}

\section{Data}

Data curah hujan yang digunakan adalah data dasarian (akumulasi 10 harian) observasi BMKG di 205 stasiun tahun 1962 sampai 2001 (Gambar 1) dan data harian luaran RegCM3 tahun 1962 sampai 2001 (kecuali tahun 1982) dengan resolusi spasial sekitar $10 \mathrm{~km} \times 10 \mathrm{~km}$.

Penelitian dilakukan dalam beberapa tahap sebagai berikut:

\section{Pengolahan Awal Data Curah Hujan Luaran RegCM3}

Data curah hujan luaran RegCM3 diubah menjadi data curah hujan dasarian $\left(\mathrm{CH}_{\text {dasarian }}\right)$ menggunakan rumus pada Persamaan (1):

$$
\mathrm{CH}_{\text {dasarian }}=\sum_{i}^{n} \mathrm{CH}_{\text {harian }}
$$

dimana:

$\mathrm{CH}_{\text {dasarian }}=$ curah hujan dasarian,

$\mathrm{CH}_{\text {harian }}=$ curah hujan harian,

$\mathrm{i}, \mathrm{n} \quad=$ hari ke-i sampai ke-n (untuk dasarian pertama tiap bulan: i adalah hari ke-1 dan $\mathrm{n}$ adalah hari ke-10, dasarian kedua tiap bulan: $\mathrm{i}$ adalah hari ke-11 dan $\mathrm{n}$ adalah hari ke-20, dasarian ketiga tiap bulan: $\mathrm{i}$ adalah hari ke-21 dan $\mathrm{n}$ adalah hari terakhir bulan yang bersangkutan).

Setelah itu, data diubah menjadi curah hujan bulanan. Data yang digunakan hanya data curah hujan bulan September-Oktober-November $(\mathrm{CH}$ soN) dikarenakan pada bulan tersebut rata-rata terjadi AMH di Jawa. Curah hujan SeptemberOktober-November ( $\mathrm{CH}$ soN) dihitung dengan rumus pada Persamaan (2):

$$
\mathrm{CH}_{\mathrm{SON}}=\sum_{i=25}^{33} \mathrm{CH}_{\text {dasarian }}
$$

dimana:

$\mathrm{CH}_{\text {SON }}=$ curah hujan observasi maupun luaran RegCM3 musiman (SON),

$\mathrm{CH}_{\text {dasarian }}=$ curah hujan observasi maupun luaran RegCM3 dasarian,

i = dasarian ke-25 sampai ke-33 (bulan September-November).

\section{Koreksi Data Curah Hujan Luaran RegCM3}

Data curah hujan luaran RegCM3 dikoreksi menurut metode Piani et al. (2010) dan dikelompokkan menjadi empat wilayah yaitu Jawa Barat bagian selatan (JBS), Jawa Barat bagian utara (JBU), Jawa Tengah-Yogyakarta (JY) dan Jawa Timur (JT) (Gambar 2). Data curah hujan luaran
RegCM3 pada masing-masing wilayah tersebut dilakukan koreksi dengan langkah sebagai berikut:

1. Menentukan jenis distribusi serta parameter data curah hujan observasi dan data curah hujan luaran RegCM3,

2. Menghitung cumulative distribution function (CDF) data curah hujan observasi dan luaran RegCM3 (Piani et al., 2010),

$c d f(x)=\int_{0}^{x} \frac{e^{\left(-\frac{x}{e}\right)}{ }_{x}^{\prime}(k-1)}{\Gamma(k) \theta^{k}} d x^{\prime}+c d f(0)$

dimana:

$\mathrm{x}$ : data curah hujan observasi maupun luaran RegCM3

$\mathrm{k}, \theta$ : parameter distribusi (untuk sebaran gamma $\mathrm{k}, \theta$ berarti shape dan scale)

$\operatorname{cdf}(0)$ : fraksi dasarian yang tidak ada hujan

3. Menghitung inverse CDF dari data curah hujan observasi dan luaran $\mathrm{RgCM} 3$,

4. Membuat plot inverse CDF curah hujan luaran RegCM3 (sumbu x) dengan curah hujan observasi (sumbu y),

5. Menentukan persamaan dari plot antara inverse CDF data luaran RegCM3 dan data observasi,

6. Menghitung data curah hujan luaran RegCM3 terkoreksi menggunakan persamaan yang diperoleh dari Persamaan (3).

\section{Uji Likelihood Ratio}

Uji ini digunakan untuk mengetahui curah hujan luaran RegCM3 terkoreksi apakah berbeda secara nyata atau sama dengan data observasi. Hasil yang diharapkan adalah curah hujan luaran RegCM3 tidak berbeda secara nyata dengan data observasi sehingga data curah hujan luaran RegCM3 tersebut dapat digunakan untuk menduga AMH. Uji ini merupakan salah satu alternatif untuk menguji data yang tidak berdistribusi normal seperti data curah hujan yang biasanya terdistribusi dengan sebaran gamma. Uji stastistika menurut Wilks (1995) pada Persamaan (4):

$A=2 \ln \left[\frac{l\left(H_{1}\right)}{l\left(H_{0}\right)}\right]=2\left[L\left(H_{1}\right)-L\left(H_{2}\right)\right]$

dimana:

$1\left(\mathrm{H}_{0}\right) \quad$ = fungsi likelihood $\mathrm{H}_{0}$

$1\left(\mathrm{H}_{1}\right) \quad$ = fungsi likelihood $\mathrm{H}_{1}$

$\mathrm{L}\left(\mathrm{H}_{0}\right) \quad=$ logaritma dari likelihood $\mathrm{H}_{0}$

$\mathrm{L}\left(\mathrm{H}_{1}\right) \quad=$ logaritma dari likelihood $\mathrm{H}_{1}$

Hipotesis yang digunakan (dengan $\alpha=0,05$ ):

$\mathrm{H}_{0}$ : parameter distribusi data curah hujan luaran RegCM3 terkoreksi sama dengan parameter distribusi observasi,

$\mathrm{H}_{1}$ : parameter distribusi data curah hujan luaran RegCM3 terkoreksi tidak sama dengan parameter distribusi observasi. 


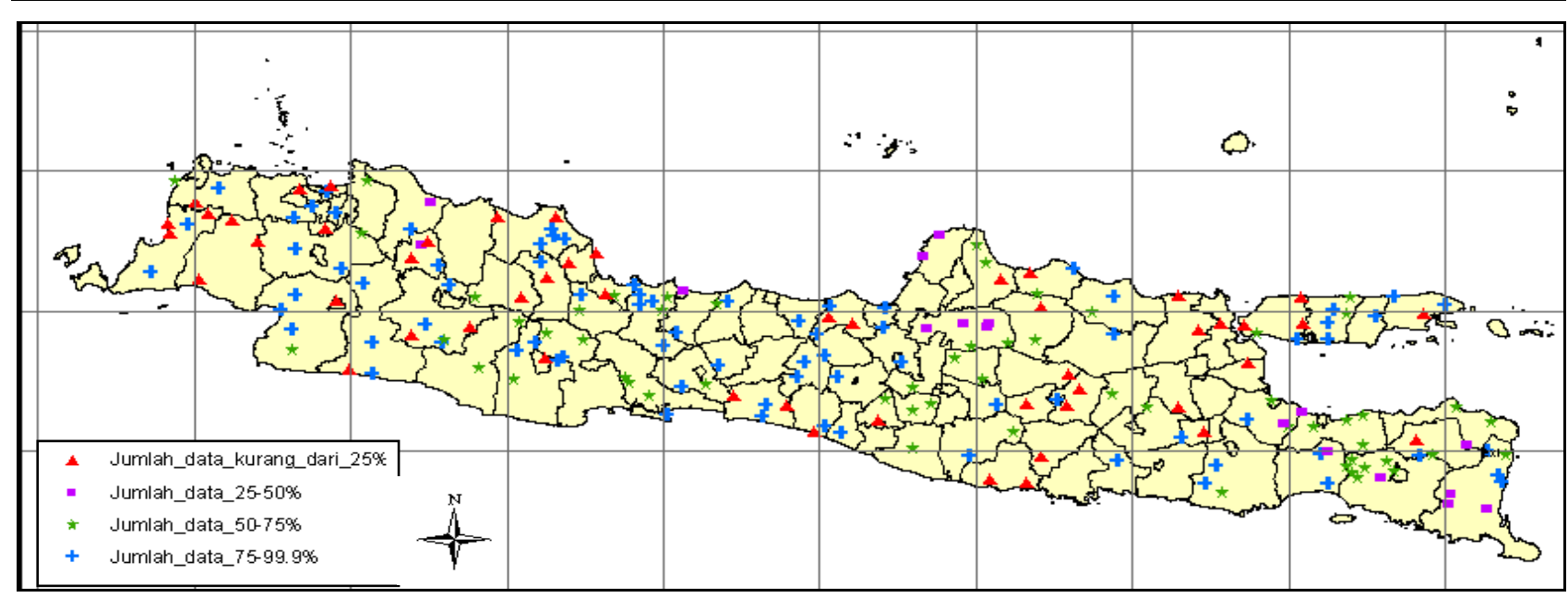

Gambar 1. Sebaran 205 stasiun klimatologi di Jawa.

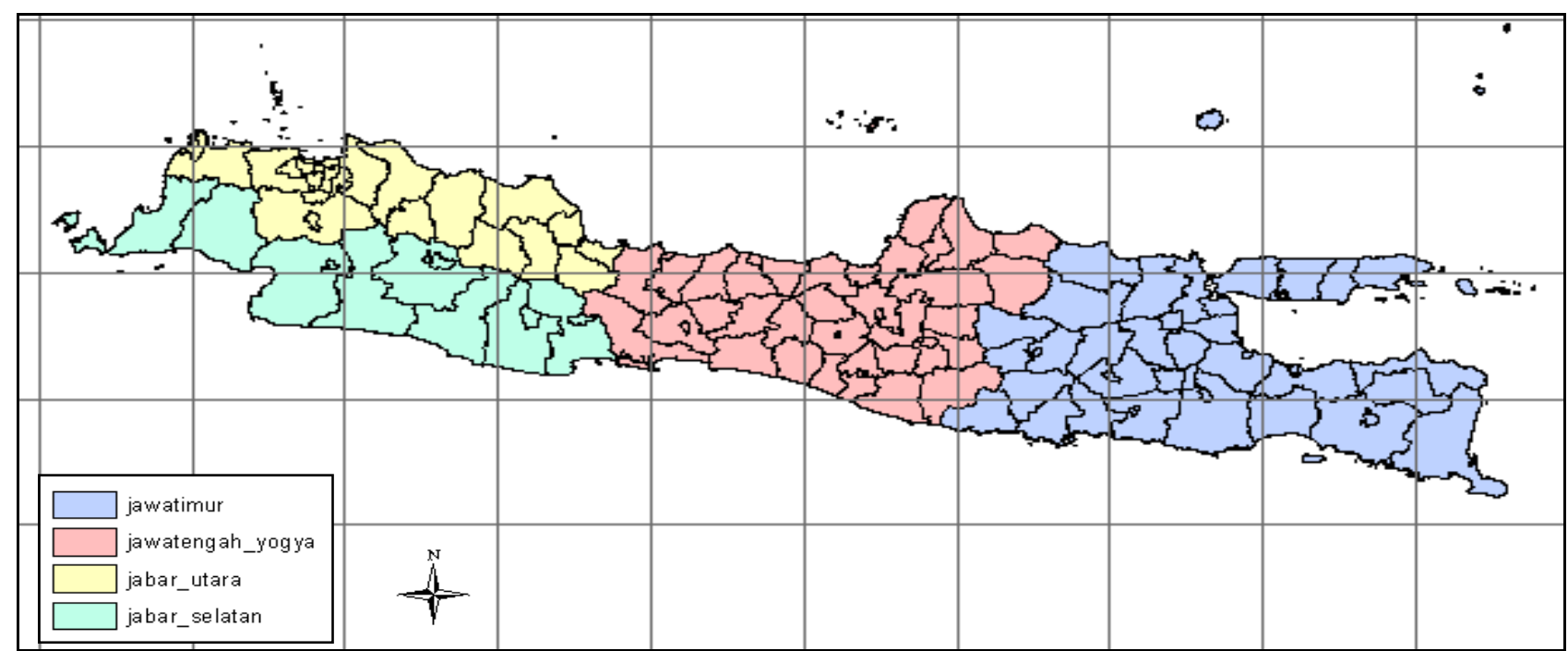

Gambar 2. Pembagian wilayah untuk faktor koreksi dan persamaan hubungan AMH-curah hujan SON.

\section{Penentuan Awal Musim Hujan (AMH)}

Penentuan AMH dilakukan dengan menggunakan kriteria BMKG dengan modifikasi dimana penentuan AMH menggunakan kriteria berjenjang:

- AMH akan dihitung setelah dasarian ke-19 (bulan Juli),

- kriteria 1: awal hujan ditandai dengan jumlah curah hujan dasarian telah lebih dari $50 \mathrm{~mm}$ dan diikuti dua dasarian berikutnya, jika kriteria 1 tidak terpenuhi maka menggunakan kriteria 2,

- kriteria 2: awal hujan ditandai dengan jumlah curah hujan dasarian telah lebih dari $50 \mathrm{~mm}$ dan diikuti satu dasarian berikutnya, jika kriteria 2 tidak terpenuhi maka menggunakan kriteria 3 ,

- kriteria 3: awal hujan ditandai dengan jumlah curah hujan dasarian telah lebih dari $50 \mathrm{~mm}$.

\section{Hubungan AMH dengan Curah Hujan SON Observasi}

Persamaan dibagi menjadi empat wilayah: Jawa Barat bagian selatan (JBS), Jawa Barat bagian utara (JBU), Jawa Tengah-Yogyakarta (JY) dan Jawa
Timur (JT) (Gambar 2). Pemilihan persamaan dilakukan dengan membuat plot AMH dengan curah hujan SON observasi dengan nilai koefisien determinasi tertinggi. Sebelum membuat persamaan maka kedua data yang digunakan dipastikan memenuhi uji asumsi yaitu kedua data berdistribusi normal.

\section{HASIL DAN PEMBAHASAN}

Persamaan hubungan curah hujan SON dan awal musim hujan (AMH) digunakan untuk memprediksi AMH di suatu wilayah jika curah hujan SON diketahui. Persamaan hubungan dibagi menjadi empat wilayah yaitu Jawa Barat bagian selatan (JBS), Jawa Barat bagian utara (JBU), Jawa TengahYogyakarta(JY) dan Jawa Timur (JT). Persamaan hubungan ini dapat berbentuk linier ataupun bentuk lainnya. Dalam penelitian ini, penentuan bentuk persamaan berdasarkan nilai koefisien determinasi $\left(\mathrm{R}^{2}\right)$ tertinggi dari plotting curah hujan SON dan AMH. Dari hasil tersebut diketahui bahwa bentuk 
persamaan yang terbaik dalam merumuskan hubungan curah hujan SON di Jawa dengan AMH adalah bentuk polinomial orde-2 atau bentuk kuadratik. Hal ini menunjukkan bahwa curah hujan yang tinggi tidak terjadi di awal (September sampai Oktober) tetapi pada bulan akhir (November) sehingga meskipun secara akumulasi curah hujan SON tinggi tetapi tidak serta merta diikuti AMH yang maju. Pengecekan terhadap kenormalan data dilakukan sebelum menentukan persamaan curah hujan SON dan AMH karena salah satu uji asumsi statistika yang harus dipenuhi adalah data berdistribusi normal. Dari empat wilayah tersebut, semua data tidak berdistribusi normal. Selanjutnya data tersebut ditransformasi agar memiliki distribusi normal. Untuk mendapatkan AMH maka dilakukan penghitungan AMH transformasi terlebih dahulu (Tabel 1). AMH transformasi merupakan data AMH yang diubah sedemikian rupa sehingga memenuhi distribusi normal. Rumus transformasi AMH untuk masing-masing kelompok wilayah kajian dapat dilihat pada Tabel 1. Persamaan hubungan curah hujan SON dan AMH dari keempat wilayah mempunyai koefisien determinasi terendah $69 \%$ dan tertinggi 86\% (Tabel 1).

Tahap selanjutnya adalah melakukan koreksi terhadap data curah hujan luaran RegCM3. Data curah hujan luaran RegCM3 terkoreksi digunakan untuk menduga AMH sesuai persamaan hubungan yang telah didapatkan sebelumnya. Persamaan hubungan antara inverse CDF data curah hujan luaran RegCM3 dan data observasi adalah polinomial orde 3 atau kubik. Hasil plot data curah hujan observasi, luaran RegCM3 awal dan luaran RegCM3 terkoreksi menunjukkan bahwa secara umum data curah hujan luaran RegCM3 terkoreksi lebih rendah dibandingkan dengan data observasi (Gambar 3). Sebagai contoh data ke-3024, curah hujan SON observasi sebesar $278 \mathrm{~mm}$ sedangkan curah hujan SON luaran RegCM3 sebesar $261 \mathrm{~mm}$. Oleh karena itu, diperlukan pengujian untuk menentukan data curah hujan luaran RegCM3 terkoreksi berbeda signifikan dengan data observasi maupun tidak. Uji yang digunakan adalah uji likelihood ratio. Hal tersebut dikarenakan data curah hujan mengikuti sebaran gamma. Hasil uji likelihood ratio menunjukkan bahwa tidak ada alasan yang cukup untuk menolak parameter distribusi curah hujan luaran RegCM3 terkoreksi tidak berbeda secara nyata (pada $\alpha=0,05$ ) dengan curah hujan observasi. Oleh karena itu, data curah hujan luaran RegCM3 dapat digunakan dalam analisis lebih lanjut.

Tabel 1. Persamaan hubungan antara curah hujan SON dan AMH.

\begin{tabular}{|c|c|c|}
\hline Wilayah & Persamaan Curah Hujan SON dan AMH & $\mathbf{R}^{2}$ \\
\hline JBS & $\begin{array}{l}\mathrm{AMH}_{\text {transfomm }}=-0.252800+0.005305^{*} \mathrm{CH}-0.000002^{*} \mathrm{CH}^{2} \\
\mathrm{AMH}=33.600000-\left(\mathrm{AMH}_{\text {transfom }}\right)^{2}\end{array}$ & $74 \%$ \\
\hline JBU & $\begin{array}{l}\mathrm{AMH}_{\text {transform }}=-0.199100+0.009048^{*} \mathrm{CH}-0.000008^{*} \mathrm{CH}^{2} \\
\mathrm{AMH}=34.686000-\left(\mathrm{AMH}_{\text {trarsform }}\right)^{2}\end{array}$ & $69 \%$ \\
\hline JY & $\begin{array}{l}\mathrm{AMH}_{\text {transfomm }}=-0.560900+0.009213^{*} \mathrm{CH}-0.000008^{*} \mathrm{CH}^{2} \\
\mathrm{AMH}=34.109000-\left(\mathrm{AMH}_{\text {trarsform }}\right)^{2}\end{array}$ & $86 \%$ \\
\hline JT & $\begin{array}{l}\mathrm{AMH}_{\text {transform }}=-0.013900+0.006323^{*} \mathrm{CH}-0.000004^{*} \mathrm{CH}^{2} \\
\mathrm{AMH}=34.286-\left(\mathrm{AMH}_{\text {transform }}\right)^{2}\end{array}$ & $80 \%$ \\
\hline
\end{tabular}

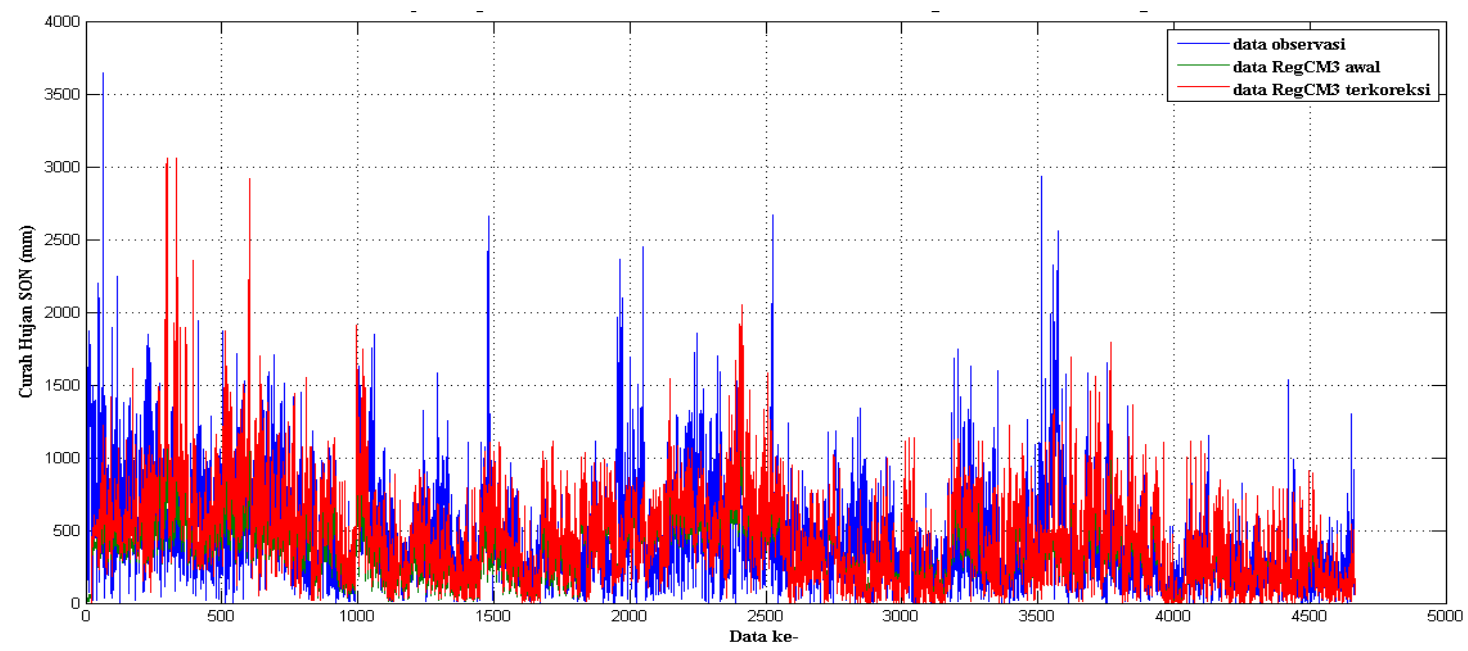

Gambar 3. Curah hujan SON observasi (biru), curah hujan luaran RegCM3 awal (hijau) dan curah hujan luaran RegCM3 terkoreksi (merah). 


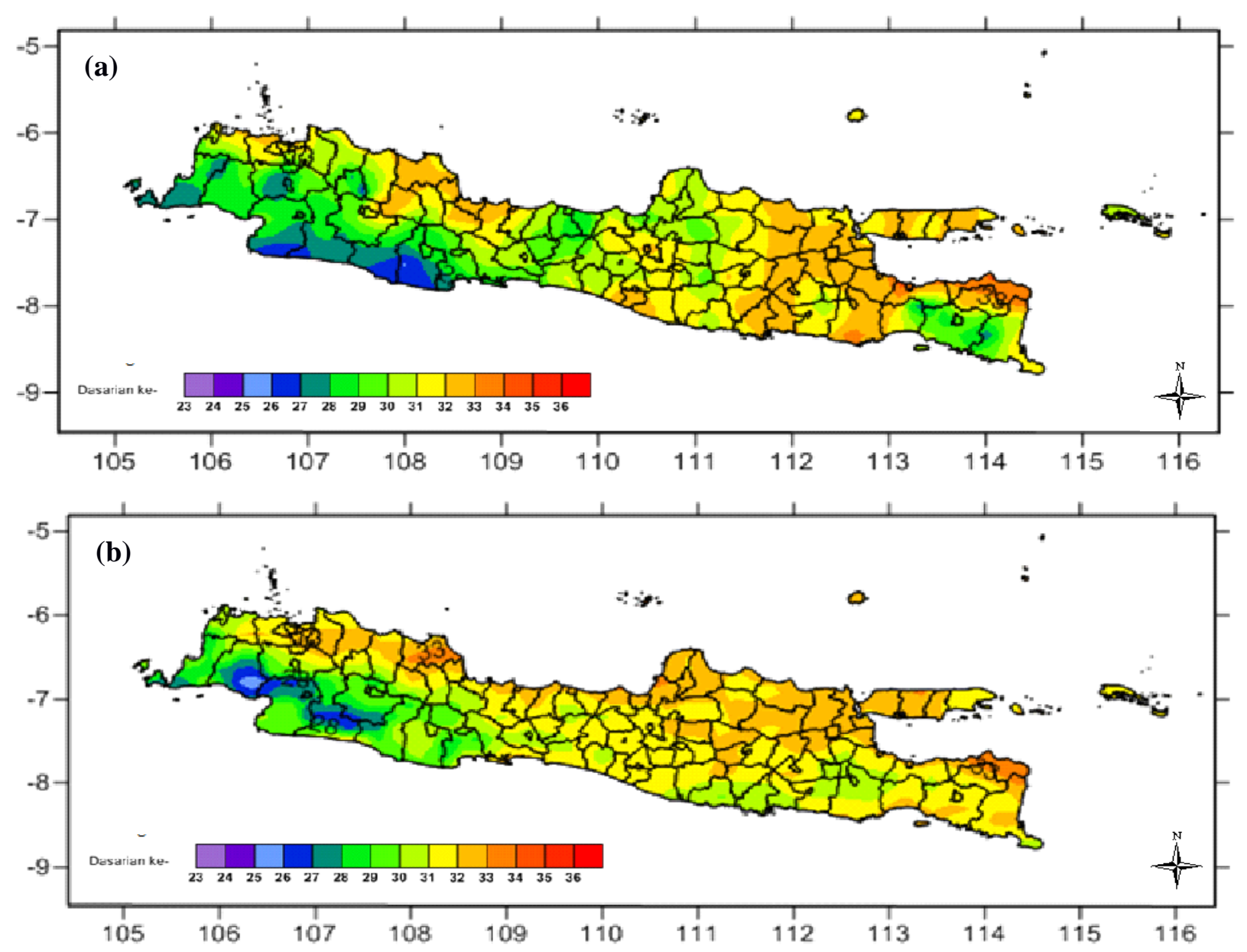

Gambar 4. Perbandingan awal musim hujan rata-rata di Jawa dengan menggunakan data observasi (a) dan data luaran RegCM3 terkoreksi (b).

\section{Penentuan Awal Musim Hujan (AMH)}

Penentuan awal musim hujan didasarkan pada kriteria BMKG (2013). Menurut BMKG (2013), awal musim hujan adalah saat curah hujan dasarian lebih dari $50 \mathrm{~mm}$ diikuti beberapa dasarian berikutnya. Oleh karena itu, peta rata-rata AMH dibuat berdasarkan kriteria tersebut dengan menggunakan dua data yaitu data curah hujan observasi dan data luaran RegCM3 terkoreksi (Gambar 4). Pembuatan peta tersebut bertujuan untuk mengetahui peta sebaran awal musim hujan di Pulau Jawa serta membandingkan hasil AMH ratarata dengan menggunakan data luaran RegCM3 terkoreksi. Gambar 4 menunjukkan bahwa awal musim hujan paling cepat di Pulau Jawa untuk data observasi pada dasarian ke-26 (dasarian ke-2 bulan September) dan paling lambat pada dasarian ke-35 (dasarian ke-2 bulan Desember). Data curah hujan luaran RegCM3 terkoreksi menghasilkan awal musim hujan paling cepat pada dasarian ke-25 (dasarian ke-1 bulan September) dan paling lambat pada dasarian ke-34 (darasian ke-1 bulan Desember). Hasil tersebut menunjukkan bahwa $\mathrm{AMH}$ hasil data curah hujan luaran RegCM3 dapat digunakan untuk mewakili data observasi. Semakin ke timur awal musim hujan semakin mundur
(Gambar 4). Hal ini disebabkan angin muson baratan (sebagai angin yang berperan terhadap datangnya AMH di Jawa) bergerak dari barat menuju timur. Akibatnya, datangnya AMH di wilayah Jawa bagian barat akan lebih cepat dibandingkan dengan AMH di wilayah Jawa bagian timur. Selain itu, daerah di pantai utara Jawa mempunyai awal musim hujan yang relatif lebih mundur dibandingkan dengan daerah di pantai selatan Jawa. Hal ini terkait topografi Jawa bagian selatan yang mempunyai ketinggian tempat relatif lebih tinggi dibandingkan dengan Jawa bagian utara sehingga Jawa bagian selatan lebih cepat mengalami hujan dibandingkan dengan Jawa bagian utara.

\section{KESIMPULAN}

Hasil penelitian menunjukkan model persamaan hubungan antara AMH dan curah hujan SON adalah polinomial orde-2 atau kuadratik dengan nilai koefisien determinasi untuk wilayah Jawa Barat Selatan, Jawa Barat Utara, Jawa Tengah dan Yogyakarta serta Jawa Timur sebesar 69\%, 74\%, $80 \%$ dan $86 \%$. Hasil uji likelihood ratio menunjukkan curah hujan luaran RegCM3 tidak 
berbeda secara nyata (pada $\alpha=0,05$ ) dengan curah hujan observasi. AMH (data luaran RegCM3) di Jawa paling cepat dasarian ke-25 dan paling lambat dasarian ke-34 (awal September sampai awal Desember).

\section{DAFTAR PUSTAKA}

[BMKG] Badan Meteorologi Klimatologi dan Geofisika. 2013. Prakiraan Musim Hujan 2013/2014 di Indonesia. Jakarta (ID): BMKG.

Boer R. and Subbiah A.R. 2005. Agricultural Drought in Indonesia. Di dalam: Boken, V.K., A.P. Cracknell, R.L. Heathcote, editor. Monitoring and Predicting Agricultural Drought: A Global Study. Oxford University Press, New York.

Boer R., Wahab I. and Hariadi M.H. 2007. Understanding Farmers' Need to Climate Information. J Meteor Geof 8(2):84-90.
De Datta S.K. 1981. Principles and Practices of Rice Production. John Wiley and Sons, Canada.

Moron V., Robertson A.W. and Boer R. 2009. Spatial Coherence and Seasonal Predictability of Monsoon Onset Over Indonesia. J Clim. 22:840-850.

Piani C., Haerter J.O. and Coppola E. 2010. Statistical Bias Correction for Daily Precipitation in Regional Climate Models over Europe. Theor Appl Climatol. 99:187-192.

Swarinoto Y.S., Pratikto A.S. dan Widiastuti M. 2009. Kecukupan Jumlah Optimum Data Penakar Hujan untuk Analisis Hidrologi dalam Daerah Aliran Sungai Kasus Daerah Aliran Sungai Brantas di Kabupaten Malang, Bul Meteo Klim Geof 5(1):117.

Wahyunto. 2009. Lahan Sawah di Indonesia sebagai Pendukung Ketahanan Pangan Nasional, Inform Pertan. 18(2):133-152.

Wilks D.S. 1995. Statistical Methods in the Atmospheric Science an Introduction. Academic Press, New York. 